\title{
As dores do mundo: pandemia e liberdade
}

\author{
The pains of world: pandemic and freedom
}

\begin{abstract}
Cesar Augusto Mathias de Alencar ${ }^{1}$
1 Doutor em Filosofia pelo Programa de Pós-Graduação em Lógica e Metafísica - PPGLM/UFRJ, com pesquisa sobre a filosofia de Sócrates a partir dos socráticos, em face do problema da condição pedagógica da Filosofia. Professor do colegiado do curso de Filosofia da UNIFAP.

E-mail: cescama@gmail.com Orcid: http://orcid.org/0000-0003-3145-0584
\end{abstract}

Resumo: Propõe-se neste ensaio uma análise filosófica dos dilemas morais e políticos a que fomos submetidos pela situação de pandemia da Covid-19. As dificuldades de muitas sociedades ocidentais no enfrentamento à pandemia têm posto em questão o paradigma liberal da preservação da vida, da privacidade e da liberdade a partir da adoção de políticas de austeridade estatal que se tornaram a orientação principal no combate ao vírus, e que parecem esbarrar nos direitos individuais, a que os orientais não parecem familiarizados. Nossa reflexão pretende oferecer, pelo recurso à filosofia da Vontade de Schopenhauer, um equilíbrio entre as posturas oriental e ocidental em vista do que nos é fundamental enquanto seres humanos: a compreensão da condição de fragilidade da vida e dos limites inerentes à liberdade individual, orientados por uma noção de justiça inevitavelmente determinada pelas dores e sofrimentos imanentes ao mundo. Diante do risco de que ações políticas se tornem tão injustas quanto as que elas pretendem combater, faz-se necessária a defesa de uma perspectiva da liberdade como ato criativo e responsável, que nos sugere ter diante dos olhos o sofrimento e a fragilidade da vida, com os quais adquirimos nossa força e nossa bondade. A cultura e a educação mostram-se, desse modo, ações mais dignas do que qualquer proposta de austeridade estatal ou de liberalidade irresponsável.

Palavras-chave: Pandemia, Liberdade, Política.

Abstract: This essay proposes a philosophical analysis of the moral and political dilemmas to which we were subjected to by the Covid-19 pandemic situation. The difficulties of many Western societies in tackling the pandemic have questioned the liberal paradigm of life preservation, privacy and freedom through the adoption of the state austerity policies that have become the main guideline in combating the virus, and which seem to bump into individual rights, to which Orientals don't seem familiar with. Our reflection intends to offer, through of the Schopenhauer's philosophy of Will, an equilibrium between Eastern and Western attitudes in view of what is fundamental to us as human beings: the understanding of the fragile condition of life and the limits inherent to individual freedom, oriented by a notion of justice inevitably determined by the pains and sufferings immanent in the world. Given the risk that political actions will become as unfair as those they intend to combat, it is necessary to defend a perspective of freedom as a creative and responsible act, that suggests to us that the suffering and fragility of life are before our eyes, with which we acquire our strength and our goodness. Thereby, the culture and education are more worthy actions than any proposal for state austerity or irresponsible liberality.

Keywords: Pandemic, Freedom, Politics. 


\section{INTRODUÇÃO}

\section{- Nestes cemitérios gerais/ não há morte pessoal. \\ - Nenhum morto se viu/ com modelo seu, especial. \\ - Vão todos com a morte padrão,/ em série fabricada. - Morte que não se escolhel e aqui é fornecida de graça.}

João Cabral de Melo Neto

O ano de 2020 já está marcado como o ano em que a Terra parou. A pandemia do chamado novo coronavírus (causador da Covid-19) se alastrou pelo planeta e alcançou proporções tais que o mundo globalizado da economia de mercado viu-se definitivamente abalado. Comércio, indústrias e serviços reduzidos ao essencial. Escolas e universidade sem aulas presenciais. Olimpíadas e competições esportivos canceladas. A face do mundo até então tido como normal mudou - e continuará a mudar. Impôs-se o paradigma da distância para diversos desses serviços, o que tornará o mundo pós-pandemia bem mais interligado virtualmente. Isso requer mais tecnologia, internet de melhor velocidade e qualidade de conexão. A tecnologia 5G é contemporânea dessa crise. Tudo isso parece confortável e promissor, mas toda comodidade traz um lado perverso - e o da vida virtual está em mascarar os sofrimentos inevitáveis da vida real.

Em paralelo a essas mudanças, o mundo ocidental tem sido levado a refletir sobre seus valores civilizacionais diante das recomendações de distanciamento e de isolamento social - postura-padrão adotada contra o avanço da pandemia e executada pelos governos com o uso de seu aparato militar a fim de impor as medidas sanitárias necessárias, ainda que para isso acabe por esbarrar na garantia dos direitos individuais dos cidadãos, como o da locomoção. O poderio financeiro da China vem, em conjunto, sinalizando aos centros de poder europeus e dos Estados Unidos um novo paradigma de austeridade política e eficiência econômica, paradigma que vê com certa estranheza nossa insistência em defender ideais como os da liberdade e da privacidade em meio a uma crise como a da Covid-19. Em artigo no jornal El País, por exemplo, o conhecido filósofo sul-coreano Byung-Chu Han ressaltou o que se deixa ver como uma crise ocidental face à eficiência social da austeridade oriental diante da crise da pandemia.

Principalmente para enfrentar o vírus os asiáticos apostam fortemente na vigilância digital. Suspeitam que o big data pode ter um enorme potencial para se defender da pandemia. Poderíamos dizer que na Ásia as epidemias não são combatidas somente pelos virologistas e epidemiologistas, e sim principalmente pelos especialistas em informática e macrodados. Uma mudança de paradigma da qual a Europa ainda não se inteirou. Os apologistas da vigilância digital proclamariam que o big data salva vidas humanas. (HAN, 2020, s.p.)

Dentre as muitas implicações que a referida eficiência do modelo oriental chinês pode provocar à reflexão, gostaria de destacar uma que me parece acentuar um problema inerentemente filosófico, e que permite ao ocidente dialogar pondo em questão, ao lado das suas dificuldades, o valor da defesa do indivíduo face à perversa política totalitária: refiro-me a implicação que põe em xeque o conceito de liberdade, concebido e defendido pelo pensamento ocidental como anteposto a qualquer poder político em que o governante exerça sua vontade a despeito dos governados. Esse conceito, formulado sobretudo em meio a diversas teorias sobre o que se conhece como contrato social, colabora ainda hoje com as noções mais gerais de dignidade da vida e da pessoa humana - também as mais específicas, da preservação dos dados pessoais e da autonomia do cidadão. Foi com base em tal noção de liberdade que nossas sociedades ocidentais 
constituíram seu ordenamento jurídico, e com referência a ela que organizações mundiais como a ONU foram criadas, com o objetivo expresso de defendê-la. Ou ao menos, deveriam.

Refletir sobre a liberdade em época de pandemia é um exercício que envolve áreas distintas do pensamento e da atividade humana, porque implica compreender a condição existencial e social na qual estamos imersos. Uma situação de crise como a da pandemia provoca nosso espírito a encarar a fragilidade da vida, o que põe em questão o esforço em lutar por determinados valores. O sentimento de nulidade e o consequente niilismo pelo qual o cidadão muitas vezes se vê acometido em tempos de crise ilustra a necessidade de que a vida, embora frágil, encontre a direção de um propósito, um sentido que lhe forneça o valor e a dignidade para defendê-la. O perigo do niilismo está em que junto a ele as posturas políticas de austeridade encontram solo fértil, na medida em que conferem um sentido político a uma vida sem sentido. Uma vida dominada por um propósito político acaba encontrando algo no que acreditar.

Essa psicologia da dominação ou, em termos morais apropriados, da injustiça que qualifica o subjugo de uma vontade sobre a outra, compôs o diagnóstico das sociedades autoritárias realizado por diversos pensadores desde Freud até Peterson, destacando aqui e ali a condescendência do dominado por sua falta de força e de orientação na vida, que explica a dominação como um caso de servidão voluntária ${ }^{1}$. A crítica filosófica e mordaz do mais aterrador dos psicólogos do século XIX condensou na força de seu pensamento uma ofensiva contra esse tipo de niilismo provocado por uma moral de ressentimento, sobretudo a partir do modelo de Schopenhauer, o filósofo da Vontade. O pensamento de Nietzsche procurou cavar mais fundo no charco que o mestre teve a força e a liberdade para denunciar (NIETZSCHE, 2011, p.193).

Mas aqui experimentamos somente as consequências desta doutrina recentemente pregada em todos os lugares: que o Estado é o fim supremo da humanidade e que não há para o homem deveres mais elevados do que servir ao Estado; reconheço nisso, não uma recaída no paganismo, mas na estupidez. Pode ser que o homem em questão, que vê no serviço do Estado seu dever supremo, não conheça efetivamente deveres mais elevados; mas isto não exime, porém, que haja outros homens e outros deveres, e um desses deveres, que a mim me parece pelo menos ser superior ao do serviço ao Estado, exige destruir a estupidez sob todas as suas formas, incluída aí, portanto, aquela forma.

É preciso ser forte o suficiente para assumir seu destino. Em sua época, Nietzsche havia se dado conta da ausência de modelos, de homens de valor que pudessem educar uma sociedade voluntariamente servil. Nenhum diagnóstico me parece culturalmente mais preciso que o da servidão voluntária de cidadãos fragilizados pelo avanço da doença em nossos dias, ao sentirem ruir sob os pés aquele pouco de estabilidade que se supunha imorredoura. O que jamais morrerá, entretanto, é a necessidade que temos de encarar a morte como destino final de uma existência que só pode alcançar valor se obtiver para si a realização daquilo que se é. E, para tanto, é preciso ter coragem para assumir livremente a responsabilidade sobre si e seu destino, de modo que a vulnerabilidade da existência se torne antes nossa força que fraqueza, nossa salvação antes que perdição. Essa havia sido para Nietzsche a mais exemplar inspiração educativa que deveríamos aprender com seu mestre Schopenhauer.

Posto esse desafio, meu intuito será oferecer uma reflexão sobre a situação de crise global da pandemia na qual estamos mergulhados, enquanto cenário cultural propício para articularmos, filosoficamente, as noções de fragilidade humana e de política autoritária como duas faces de um mesmo dilema: o de sabermos até onde o ser humano pode e deve ser privado de sua liberdade, ou até onde ela deve lhe ser assegurada, a

${ }^{1}$ Cf. FREUD (1930) e PETERSON (2017). Sobre o conceito de servidão voluntária, ver ainda a conhecida obra de LA BOÉTIE (1563). 
fim de que a ação livre, que nos dignifica como humanos, não se transforme em subjugo e dominação - ou em outras palavras, não se torne injusta e perversa. Há dois caminhos para tornar fértil o momento de crise que vivemos: é preciso encarar o fenômeno da dor e da morte ou pela perspectiva da contemplação filosófica, ou pela piedade frente à dor alheia. Nos dois casos, veremos, a liberdade da ação criativa na qual florescem a cultura e a educação é a mais valorosa realização de que podemos sair em defesa.

\section{LIBERDADE E JUSTIÇA POLÍTICA}

O avanço da Covid-19 e o decreto de pandemia pela OMS marcaram o noticiário mundial em finais de fevereiro e início de março de 2020, embora a doença tivesse sido já diagnosticada em finais de 2019. Da cidade de Wuhan, na China, epicentro inicial da pandemia, a Covid-19 alastrou-se para o Irã e a Europa, causando um abalo no sistema de saúde e um acúmulo do número de mortes em países como a Itália e a Espanha. Devido à alta taxa de transmissibilidade do vírus, sugeriu-se como protocolo o isolamento social, o recurso mais imediato e eficaz contra a rápida propagação da doença. Devido ainda à síndrome respiratória aguda provocada pelo vírus, tentou-se desenhar um certo perfil de risco de morte, sobretudo em vista da faixa etária e de condições clínicas associadas, que parecia justificar as medidas restritivas adotadas ao redor do mundo a fim de conter os casos graves da doença, passíveis de evoluir à óbito.

Quem acompanhou noticiários e mídias sociais, pôde perceber o dilema no qual fomos encerrados enquanto sociedade: acatar as determinações políticas de autoridades sanitárias e evitar sair de casa, ou continuar as atividades econômicas e sofrer possíveis sanções do aparato policial do Estado. Os debates midiáticos enfocaram constantemente a difícil decisão entre instituir ou não uma política austera de isolamento social, conhecida como lockdown, por parte dos governantes, enquanto para a população o dilema impõe-se entre apoiar ou não tais políticas, pondo-se a cumpri-las ou burlá-las. Normalmente, o movimento dos que se põem a burlá-las deve-se à necessidade econômica, pois a maior parte das pessoas precisam continuar a trabalhar ou terão dificuldades para sobreviver. Essa mesma necessidade econômica tem levado estados e municípios a ponderarem qual a hora certa para adotar medidas mais austeras, repercutindo na opinião pública um tipo de conflito entre economia e saúde que, a bem da verdade, é aparente.

Dentre os mecanismos estatais para controlar a situação de alastramento da doença e para fazer cumprir a política de isolamento social pelos cidadãos, alguns governadores brasileiros, como o de São Paulo e do Rio de Janeiro, por exemplo, valeram-se dos dados de usuários oferecidos por empresas de telefonia celular com o intuito de identificarem zonas de aglomeração na cidade. Ainda que os dados fossem disponibilizados em bloco e sem quebra de privacidade, a mídia e as redes sociais repercutiram críticas ao uso desses dados com a denúncia de que se fazia avançar os tentáculos do Estado sobre a privacidade das pessoas - o tipo de argumento usado pelos mesmos que criticaram a restrição pública da circulação dos cidadãos, por entenderem que com tal medida o Estado cerceia o direito individual à liberdade. Diante desse tipo de posição, somos levados a refletir sobre até que ponto a defesa da liberdade individual pode fechar os olhos aos interesses coletivos.

Para um Estado Democrático de Direito, como é o caso entre as nações ocidentais, a liberdade individual deve ser garantida ao lado do direito à vida e à segurança, tripé fundamental para a política liberal². Mas o direito, enquanto garantia social, está fundado sobre a noção de justiça, noção que é antes moral que política. Dito de outra forma, a justiça, que só pode encontrar sua razão de ser no âmbito da moral, está na

\footnotetext{
2 Para uma análise abrangente do liberalismo e suas variadas vertentes, ver MERCHIOR (2014).
} 
base de todo e qualquer direito social. Pode-se ter por justiça a limitação de um ato de vontade que atenta contra - porque pretende subjugar - a vontade a ser manifesta por um outro.

A injustiça é o caráter próprio da ação de um indivíduo que estende a afirmação da vontade enquanto manifestada pelo seu próprio corpo, até negar a vontade manifestada pela pessoa do outro (SCHOPENHAUER, 1819, p. 355).

O subjugo da vontade alheia é a matriz schopenhaueriana para um ato injusto. A política, portanto, seria a desejável realização da razão no interesse pela manutenção de certo equilíbrio social entre vontades individuais. É por isso que, na perspectiva da moral, o ato de correção de alguma injustiça cometida pode ser tido como relativamente injusto, por se propor a subjugar, secundariamente, uma vontade que, primeiramente, subjugou outra. Politicamente, no entanto, esse ato correcional do Estado se faz legítimo, pelo intuito de tornar outra vez viável o equilíbrio social ${ }^{3}$.

Se é preciso hastear a bandeira dos direitos individuais, não podemos hasteá-la desconsiderando sua natureza social. Aqui mora todo o problema dos atos políticos em um Estado de Direito. Segundo o parecer de Schopenhauer, ao Estado não interessa senão os atos - e por serem eles precedidos de motivações, à política não interessam motivações, apenas a injustiça realizada. Ao que parece, mantém-se aqui o fosso que separa a política da moral desde Maquiavel - só que a educação clássica fala mais alto em Schopenhauer. Embora ao Estado só interesse o ato injusto (já que o ato justo, como correção da injustiça cometida, torna a justiça um fato secundário e consequente), a ação política, com vistas a evitar que injustiças sejam sofridas, não pode se furtar à avaliação moral dessas ações, pois cabe à moral evitar que injustiças sejam cometidas. $\mathrm{Na}$ medida em que os governados tanto quanto os governantes encontram-se, para o filósofo alemão, legitimados pela noção do ato moralmente justo, e da justiça como direito natural, o que há é não uma separação entre moral e política, mas a derivação desta daquela.

De tudo isso a razão conclui que caso se queira, primeiro, enfraquecer a soma dos sofrimentos a ser repartida entre os indivíduos, e também reparti-la o mais uniformemente possível, o melhor meio, o único, é evitar a todos a mágoa da injustiça recebida, e para isto, fazer renunciar a todos o prazer que a injustiça cometida pode dar (SCHOPENHAUER, 1819, p. 360).

A proposta de Schopenhauer, ao pensar a política, está em orientá-la sob o parecer da justiça, derivando a justiça, por sua vez, de um parecer da moral. Portanto, é no âmbito da moral que o mundo, como uma Vontade cega, se torna aceitável à consciência humana, por ser na consciência que a justiça se realiza.

Dado que a Vontade do mundo (denominação empregada por Schopenhauer para dizer a essência que não pode ser conhecida, mas percebida pela intuição ${ }^{4}$ ) se manifesta a partir de Representações (as manifestações individuais e particulares dessa essência do Ser), esse mundo representado engana

3 Sobre o que pode ser tomado como uma teoria do estado na obra de SCHOPENHAUER, ver 1819, p. 347.

4 Schopenhauer nos esclarece a adequação do seu uso do termo Vontade para nomear esta essência imaterial do mundo: "Devo, contudo, observar que apenas me sirvo então de uma denominatio a fortiori, pela qual dou ao conceito de vontade uma extensão maior do que a que ele tinha até aqui. Reconhecer o que é idêntico nos fenômenos diversos, e o que é diferente nos semelhantes, aqui está, Platão repetiu-o muitas vezes, uma condição para filosofar. Ora, não se tinha reconhecido até hoje que a essência de toda energia, latente ou ativa, na natureza era idêntica à vontade, e consideravam-se como heterogêneos os diferentes fenômenos, que são apenas as diversas espécies de um gênero único: resultava daí que também não podia haver uma palavra para exprimir o conceito deste gênero. Denominei, portanto o gênero segundo a espécie mais perfeita, cujo conhecimento fácil e imediato nos conduz ao conhecimento mediato de todos os outros" (SCHOPENHAUER, 1819, p. 120; grifos do autor). 
constantemente aqueles incapazes de olhar para além das formas da sensibilidade, reduzindo tudo o que existe à multiplicidade que nos distingue e separa. O mundo como Representação, conhecido pelo entendimento, expõe-se como um mosaico de entes em guerra, na medida em que são impelidos à afirmação de sua própria existência; inadvertidamente, a despeito dos demais. Essa ilusão de Maya, esse véu que nos oculta a essência da Vontade, Schopenhauer nos mostra, é a raiz de todo sofrimento. Sua filosofia da Vontade tece uma explicação sobre a dor e o sofrimento como inerentes à condição do mundo, onde os atos injustos desencadeados por essa guerra de todos contra todos justificam o interesse humano pela aplicação da racionalidade política como instrumento de contenção das vontades cegas e insaciáveis. Se ao Estado não cabe produzir felicidade, ele deve buscar ao menos evitar o sofrimento dos seus cidadãos.

A Vontade, por ser este querer cego e insaciável, impele à ação os indivíduos em busca de satisfação, impele a que os entes afirmem sua própria existência. A necessidade que movimenta a Vontade perpetuamente - visto que insatisfeita - é a raiz do sofrimento não apenas porque ela própria, como uma falta, jamais pode ser completamente satisfeita, mas também porque os homens, desejosos de se afirmarem, por vezes o fazem uns contra os outros, sem se darem conta de que todos são, enquanto Vontade, a mesma realidade. Para Schopenhauer, o remorso, como sentimento de dor que fere a consciência moral após um ato injusto (SCHOPENHAUER, 1819, p. 351), se destaca em nossa psicologia ao expressar a intuição da realidade que somos, da essência que partilhamos com o mundo. Se o conhecimento racional nos leva ao engano de tomarmos como real a representação fenomênica dos entes, a intuição da Vontade que nos une justifica a consciência moral no apelo criativo da liberdade, a partir da qual a razão se esclarece sobre a verdadeira causa do sofrimento. E o ser humano é o único em condições de poder neutralizar o sofrimento a partir do ato criativo da liberdade.

Isso porque a Vontade é em si mesma liberdade, no sentido mais amplo do termo. Os atributos com que Schopenhauer caracterizou a Vontade (SCHOPENHAUER, 1819, p. 120) descrevem-na em termos de uma força soberana que só pode ser neutralizada por si mesma. Para tanto, é preciso que a Vontade se dê conta da realidade de sua condição: ela se torna incapaz de ser plenamente livre porque determinada pelos limites da dimensão material do espaço-tempo na qual ela se manifesta, e sem a qual ela nada seria. Os limites ao exercício de sua força livre conformam, portanto, os meios através dos quais ela chega a obter uma representação de si mesma no ser humano: afinal, uma liberdade sem limites se destrói. O desejo de quererviver esse limite conduz a Vontade à compreensão de que no mundo, como representação, não há espaço para a felicidade. A liberdade, desse modo, não pode se referir à busca da felicidade, mas à compreensão da realidade do sofrimento como essencial aos entes; ela não se refere a um ímpeto de fazer tudo aquilo que se quer, mas a uma consciência de si que a demove de toda ilusão sobre o mundo, o que a torna capaz de desprender-se do perpétuo querer-viver para, negando-se, realizar-se livremente (SCHOPENHAUER, 1819, p. 429).

Como o próprio Schopenhauer pondera, essa concepção desfaz de uma vez aquela insistente dicotomia que permeou grande parte da filosofia moderna, dividida entre supor haver o predomínio da liberdade sobre a necessidade ou vice-versa (SCHOPENHAUER, 1819, p. 121). Pois não há, nem pode haver, liberdade e necessidade plenas e absolutas. No território do humano, onde se dá a consciência do embate, a Vontade, essencialmente livre, se manifesta como Razão, capaz de conhecer o que há de representativo e, portanto, de necessário no mundo. A cadeia causal que entrelaça os fenômenos por necessidade só pode ser rompida pela intuição contemplativa da Vontade sobre ela mesma, de tal modo que a fórmula schopenhaueriana que nos fala da negação da Vontade expressa o paradoxo da própria essência do real - que, livremente, se volta contra sua aquiescência diante da necessidade, contra o sofrimento que o mundo da Representação 
lhe causa. Se no mundo da manifestação a Vontade é levada a sofrer por necessidade, ela o faz livremente, porque só na Representação ela se neutraliza com a consciência de ser o que é.

Já que é no mundo da Representação que a Vontade se realiza, ela precisa fazê-lo através de entes individuais. Os indivíduos, como parte da ilusão de Maya, não devem ser moralmente afirmados, visto que cada um é essencialmente um com o todo: cada um é em si mesmo Vontade. O ato injusto, como vimos, se dá pela dominação de um ente sobre o outro, quando se procura impedir no segundo a realização da Vontade essencial que está também presente no primeiro $^{5}$. É forçoso admitir, desse modo, que determinar o ato injusto, enquanto base da moral e da política, é obra da Razão. E já que a Razão lida com conceitos (o instrumento adequado para se obter conhecimento sobre a necessidade causal dos fenômenos), encontra-se aqui um paradoxo inevitável que põe em xeque a noção que ainda utilizamos de liberdade: visto que a Vontade livre depende dos indivíduos para se realizar e que sua realização se dá pela consciência de sua necessidade, a Vontade só pode ser dita efetivamente livre quando capaz de negar a si mesma.

Isso nos traz de volta àquela oposição flagrante que se depreende do dilema ao qual estamos lançados em contexto de pandemia: deve-se limitar a liberdade individual quando ela atenta contra a responsabilidade social? Segundo a reflexão sobre a liberdade oferecida por Schopenhauer, a boa consciência - quer dizer, a atitude contemplativa que intui a condição essencial ao mundo a fim de poder realizar verdadeiramente a liberdade da Vontade pela negação de seu sofrimento na Representação - nos leva a retomarmos a noção de liberdade individual enquanto necessariamente relativa, e por isso recíproca ao conceito de responsabilidade, tanto individual quanto social (embora creia ser esta uma distinção aparente, já que não parece haver responsabilidade que não seja, de todo modo, relacionada a um outro). Ou seja, não é possível promover a liberdade contrariando seu território de manifestação coletiva. Também não é possível, contudo, suprir as liberdades individuais em vista de uma vontade social única, porque não há realização humanamente digna fora da consciência moral livre. O problema ético e moral envolvido nesta questão, a de saber coadunar a autoridade estatal com as liberdades individuais, traz implicações políticas decisivas, e não se encontra facilmente respostas satisfatórias para ele entre os atuais debatedores.

O que a reflexão schopenhaueriana nos oferece é a contemplação filosófica como um meio para evitarmos o engano abstrativo e individualista que muitas vezes cega nossa defesa da liberdade no ocidente. Constatamos a disposição de muitos para uma afirmação intransigente da ação livre a ponto de ausentá-la, não raro, das responsabilidades coletivas com as quais ela está comprometida. A hermenêutica do real oferecida por Schopenhauer, é verdade, torna a própria condição do indivíduo uma ilusão. Afinal, se essencialmente o mundo é Vontade e nada além disso, pode ser que o discurso que atente contra os direitos da pessoa humana esteja legitimado em vista de uma felicidade comum. Mas já vimos que a legitimidade dos atos do Estado, para Schopenhauer, encontra-se na punição a ações injustas com o intuito de restabelecer o equilíbrio das forças individuais. A justiça política só estará bem fundamentada se a punição a tais ações tiver como propósito a educação de seus cidadãos, sem que o Estado incorra ele mesmo em cometer injustiças. O exercício do poder sem a justificativa moral da educação dos cidadãos é igualmente uma crueldade injusta.

\footnotetext{
${ }^{5}$ Não se pode esquecer de que foi esse moralismo a razão principal das críticas de Nietzsche ao seu mestre, a partir do texto da Consideração Intempestiva sobre Schopenhauer como educador. Vale dizer que, em Nietzsche, essa Vontade que se sobrepõe a de um outro se tornará o modelo para o controverso conceito da Vontade de Potência. Sobre isso, ver MÜLLER-LAUTER (1997).
} 


\section{PANDEMIA E FRAGILIDADE HUMANA}

A pandemia e as políticas adotadas para conter o seu avanço trouxeram à discussão algumas questões humanas imorredouras, que ou estavam adormecidas ou não ocupavam o centro da vida moderna na intensidade com que elas hoje se expõem. Para a atividade filosófica, no entanto, tais reflexões estão sempre à flor da pele, na medida em que nossa tarefa está em conduzir da melhor maneira possível o pensamento até ao ponto em que se pode contemplar a raiz e o fundamento das nossas dúvidas e inquietações na vida, com a certeza de que esta contemplação, embora aparentemente inútil e improdutiva, oferece aos seres humanos o encontro mais fidedigno com sua aspiração existencial - ou seja, um sentido para tudo o que nos pomos a fazer e a produzir de útil.

Épocas de crise são, por definição, momentos de dilaceramento daquilo que dava mostras de permanecer inalterado. Krísis em grego é bifurcação, ruptura, palavra que está na origem do nosso termo crítica, cujo sentido abrange a noção de delimitação, de análise. É próprio da crítica, portanto, provocar o pensamento a uma crise. E se, ao ser humano, a morte se apresenta como o pensamento mais crítico, isso decorre da consciência que temos acerca da fragilidade da vida. A bem da verdade, já dizia Heráclito, nada permanece o mesmo, tudo muda - e essa mutabilidade se amplia no âmbito dos processos da vida de tal modo que constatamos sua fragilidade e inconstância à olho nu. A fragilidade da vida, que se deixa sentir em plantas e animais menos complexos, é revelada para nós pelas dissoluções e rupturas desencadeadas em contextos de crise intensa, como a que vivemos com a pandemia da Covid-19. No entanto, a doença e a morte que nos ferem fazem parte do espetáculo de dor naturalmente necessário para que a vida continue a existir: a semente sufocada morre para dar vida à planta - mais exuberante que ela, e também mais frágil.

Uma visão da realidade da crise precisa ser crítica e, por paixão, trágica. Envoltos pelos ventos da tempestade que nos assola, é difícil ver além do que a poeira nos permite, a não ser que adotemos um ponto de vista externo ao olho do furacão e que, de um modo ou de outro, torne possível oferecer diagnósticos e previsões. A análise crítica e o sentido trágico necessários a esse momento de crise encontram junto à reflexão de Schopenhauer um ponto de vista que, embora denunciado como pessimista, se mostra bastante realista. Não interessou ao filósofo alemão produzir um lamento niilista diante do sofrimento pelo qual a vida floresce, como se à filosofia fosse possível fugir do inevitável. É preciso ter coragem para afirmar a vida em seu sofrimento, "e nós vamos audaciosamente até o fim” (SCHOPENHAUER, 1819, p. 431). Com sua perspectiva corajosa, Schopenhauer abriu caminho para uma filosofia do corpo e da vida ainda hoje tão frutíferas quanto a realidade do inconsciente, o solo em que nasceu a psicanálise freudiana. O grau de influência da teoria schopenhaueriana nos diversos ramos do saber ainda não chegou a ser devidamente mensurado ${ }^{6}$.

Quero aqui enfocar a noção-chave para essas influências, a fim de servir de meio para produzirmos uma reflexão capaz de dar sentido às escolhas que precisam ser feitas em tempos de pandemia. Refiro-me a própria Vontade como centro da proposta filosófica de Schopenhauer, e que me parece decisiva para nos situar diante do dilema a que fomos envolvidos quanto ao interesse pela preservação da vida e da liberdade. E falar de vida e de liberdade é atentar para o lugar em que elas se manifestam - ou seja, no corpo.

A essência íntima destas manifestações e ações do seu corpo ser-lhe-ia incompreensível: chamarlhe-ia como lhe agradasse, força, qualidade ou caráter, e não saberia nada mais por isso. Mas não acontece assim; longe disso, o indivíduo é ao mesmo tempo o sujeito do conhecimento e encontra aí

\footnotetext{
${ }^{6}$ Há alguns esforços nesse sentido, como em REDYSON, 2009, p. 95.
} 
a chave do enigma: essa palavra é Vontade. [...] A Vontade é o conhecimento a priori do corpo; o corpo é o conhecimento a posteriori da Vontade. (SCHOPENHAUER, 1819, p. 109-110; grifos do autor)

Os filósofos modernos conhecidos como contratualistas já haviam esclarecido de que forma as sociedades surgem com o propósito de preservar a vida humana. O primeiro deles, Thomas Hobbes, é destacado por Schopenhauer (1819, p. 358) por ter oferecido uma compreensão lapidar da origem e da finalidade das sociedades, ainda que o filósofo alemão não estivesse inclinado, como John Locke não estava, em assumir a necessidade de um poder monocrático como o do Leviatã. Mas Schopenhauer não se mostra também muito afeito à defesa lockeana da liberdade como valor humano, por tê-la justificado em função da ordem divina ${ }^{7}$. Mais próximo de Hobbes, a teoria da Vontade schopenhaueriana vê a vida como valor primordial em relação ao qual os indivíduos, egoístas por natureza, expõem-se ao conflito constante, atormentados pelo medo que ameaça à sua segurança. A justificação para esse estado de guerra de todos contra todos, em cujos atos injustos se assentam as bases da necessidade política do Estado, coaduna a dinâmica biológica tanto com uma metafísica quanto com uma psicologia, todas elas imanentes ao mundo que se trata de explicar.

A dinâmica da vida humana, como a dos demais seres viventes, constitui-se de fenômenos da Vontade, ou seja, como Representações. O dito princípio de individuação, que constrange a essência do mundo a adotar formas múltiplas e variadas, é o reduto da noção que usamos para defender a vida e a nossa pessoalidade. Vimos, na primeira parte deste ensaio, de que maneira a Vontade, que é por natureza falta e que por isso constitui a raiz de todo sofrimento, deve nos conduzir ao conhecimento pelo qual a liberdade pode se realizar. Mas esta essência de todos na Vontade universal, alguém poderia dizer, não parece justificar qualquer interesse da vida em preservar os indivíduos que a manifestam: se a Vontade que se manifesta é a mesma em cada fenômeno, não parece importar muito se esse ou aquele ente é aniquilado. Se em tudo o que existe só há Vontade, e nada além disso, o que justifica o valor de uma existência perante as demais?

Schopenhauer, ciente desse problema, soube encontrar uma teleologia da natureza na existência humana, pois no ser humano a Vontade, pelo conhecimento, se manifesta mais claramente naquilo que ela é, ou seja, ato criativo de liberdade. Mas a Vontade age também onde o conhecimento não pode orientá-la, ou seja, naqueles seres incapazes de representação. E se ela parece ser determinada nos chamados seres inorgânicos, como a pedra, e dotada de livre-arbitrio em nós, é preciso contatar de um ao outro uma gradação de realidade cuja essência, embora livre para se manifestar onde queira, estará regida pela causalidade que liga necessariamente a causa e o efeito. Eis uma perspectiva que altera a orientação de Spinoza: se o filósofo geômetra pôs em paralelo a determinação causal nas pedras e nos humanos, tornando ambos desprovidos de liberdade, para Schopenhauer, ao contrário, é a Vontade, em sua indeterminação essencial, que se realiza livremente tanto nos humanos quanto nas pedras ${ }^{8}$. A diferença de grau de objetivação e de manifestação dessa Vontade é no ser humano apenas mais consciente de si mesma. No ser humano, a ideia, eterna e una, o paradigma das coisas existentes e manifestadas, é mais plenamente compreensível.

Schopenhauer aqui segue o princípio aristotélico, que nos orienta a buscar saber sobre o que não conhecemos partindo do que conhecemos. Esse princípio metodológico, no entanto, torna-se princípio ontológico para o filósofo alemão: a Vontade é mais real naqueles em que ela melhor se faz conhecer. A distinção entre os homens e os animais se eleva, com isso, a um grau de manifestação da Vontade bem mais

7 Sobre a teoria da liberdade e do poder nos filósofos citados, ver HOBBES (1851) e LOCKE (2007).

8 Para a diferença de perspectiva que Schopenhauer apresenta frente à de Spinoza, ver SCHOPENHAUER, 1819, p. 135. 
individual e específica: prova disso é que o instinto sexual, no ser humano, é fruto de escolhas levadas tão longe pelo sentimento dedicado a um outro de nós que chega a degenerar em violenta paixão. Há para Schopenhauer uma implicação fundamental que se depreende dessa distinção, ao observarmos as espécies animais: é possível chegar a prever as ações de um indivíduo de determinada espécie animal, simplesmente conhecendo a família a que ele pertence. Não se pode pretender o mesmo com qualquer indivíduo humano. A razão está em que nos humanos a ideia que dá forma aos entes se manifesta para cada indivíduo particularmente.

Assim, pois, o homem aparece-nos como uma manifestação particular e caracterizada da vontade, em certa medida, como uma ideia particular; os animais, ao contrário, têm falta deste caráter individual, visto que só a espécie tem uma significação particular e que os traços de caráter desaparecem à medida que nos afastamos do homem; as plantas não têm outras particularidades individuais senão as que resultam da influência favorável ou desfavorável do clima, ou de qualquer outra circunstância. Toda a individualidade desaparece, finalmente, no reino inorgânico da natureza (SCHOPENHAUER, 1819, p. 140 §26).

Proponho com a exposição dessa caracterização da Vontade subjacente ao mundo manifestado, pela qual Schopenhauer argumenta sobre o valor individual dos humanos, pensarmos a fragilidade de nossa condição existencial antes como sendo a nossa força. É de fato como um espetáculo de luta entre manifestações diversas da Vontade que a ideia superior chega a se manifestar, assimilando triunfante as ideias inferiores e, com isso, esclarecendo cada vez mais o caráter e o destino da vida. Esse espetáculo fisiológico dá-se para o ser humano, ao final, como um espetáculo estético: a contemplação das ideias, prerrogativa do artista e do gênio criador, está na realização final que o sofrimento tende a provocar na alma, por uma intuição da beleza na gratuidade da vida como liberdade de criação. Por isso, é na arte que a Vontade, divorciada de si mesma pela multiplicidade de manifestações objetivas a que se submete no mundo da Representação, reencontrase com seu destino no homem criador.

É apenas no âmbito da arte, no homem como artista e gênio contemplativo, que a individualidade deve ser suprimida - afinal, trata-se do reflexo, do reencontro da Vontade essencial consigo mesma na consciência humana. Essa supressão jamais é definitiva, pois será sempre numa consciência individual que a Vontade se reencontrará consigo. Ela é, antes, a capacidade de alcançarmos a incondicionalidade do tempo, a eternidade e unidade que são a essência do que somos. Essa contemplação de nossa eternidade como ideia foi aquilo mesmo que Nietzsche (2011, p. 212-214) nos convidava a fazer a partir de sua leitura de Schopenhauer como educador: a filosofia da Vontade deste último serviu para o primeiro como um tipo de obra de arte, na qual ele pôde descobrir o seu destino. Eis a verdadeira finalidade da educação - educar será sempre ensinar a contemplar. Tanto o artista como o espectador são capazes dessa genialidade criativa na contemplação - “a vontade é uma só e idêntica no objeto contemplado e no indivíduo” (SCHOPENHAUER, 1819, p. 189, §34). Para nós, torna-se compreensível por que, em Nietzsche, a cultura era a única justificativa para a existência, em relação à qual os homens mais fracos encontram o sentido de sua vida no exemplo dos homens de gênio e de força - força esta que não é física, e sim espiritual e artística (NIETZSCHE, 2011, p. 212-214).

É, portanto, na arte como livre criação, e na contemplação crítica da realidade do sofrimento, que podemos superar a limitação imediata de nossa condição existencial: ao tornar-se o que é, o ser humano pode encontrar na dor e na morte o valor e a dignidade que dão sentido à existência. Isso não ocorre por meio nem da política nem da moral, mas pela cultura e educação, que devem ser ambas obras de gênio. Uma 
cultura sem gênios que lhe sirvam como paradigma, como modelo e ideia, está fadada a degenerar-se em liberalidade ou totalitarismo. O equilíbrio das Vontades se dignifica pela arte. E a arte depende dos homens de gênio, com sua liberdade criativa, para não degenerar em cultura de entretenimento.

\section{CONSIDERAÇÕES FINAIS}

A pandemia da Covid-19 tem feito com que o ocidente enfrente um dilema moral dos mais significativos, porque esbarra em nossa liberdade de ser e em nosso sentido de existir. Encerradas na confrontação entre uma postura de austeridade, cujo centro político tende a se determinar pela vontade do governante sobre a dos governados, e uma política de liberalidade, cuja realização orienta-se pela consciência de cada um em vista da função que pode e deve exercer para o bem de todos, as sociedades ocidentais foram convidadas pela crise a repensar seus valores mais caros, a fim de encontrar na aparente fragilidade a sua verdadeira força. A filosofia da Vontade de Schopenhauer mostrou-nos um caminho, ao oferecer a perspectiva da liberdade como ato criativo e responsável, sugerindo-nos ter diante dos olhos o sofrimento e a fragilidade da vida, com os quais adquirimos nossa força e nossa bondade. Para tanto, faz-se preciso não perdermos este momento.

Parecemos, no entanto, estar longe de encontrar os gênios criativos em condições de nos elevarem à realização de nosso destino. Num dos mais belos parágrafos de sua obra magna, Schopenhauer nos legou sua descrição do choro, e do riso em paralelo, como a qualidade tipicamente humana, porque capaz de favorecer em nós as ações boas e o valor da bondade (SCHOPENHAUER, 1819, p. 395). No choro, estamos diante de um espelho: pela dor alheia, que não podemos sentir, apenas imaginar, representamos em nós o que significaria essa dor se estivéssemos no lugar do outro. Nessa psicologia do choro há o que se costuma chamar de empatia - e que não corresponde necessariamente a uma identificação com o outro, mas a um sentimento complexo de piedade de si mesmo. É no espelho dessa piedade, raiz do choro, que a Vontade procura um alívio para o mal do dilaceramento e da luta intestina que traduz a condição de toda existência. Quando nos faltam os gênios capazes de elevar a cultura humana, resta-nos o fenômeno da morte e a dura realidade de sua lição. Podemos alcançar a força criativa da consciência livre também a partir da contemplação da Vontade nesse espelho que, em piedade, enxergamos o que somos na morte - afinal, "se há alguma coisa que nos envergonha em semelhante ocasião é não chorar” (SCHOPENHAUER, 1819, p. 396).

\section{REFERÊNCIAS}

FREUD, S. (1930) 0 mal-estar da cultura. Tradução Renato Zwick. Porto Alegre, L\&PM, 2018.

HAN, B-C. (2020) “O coronavírus de hoje e o mundo de amanhã”. El País/Brasil, Ideas: 22.03.2020. Acessado em 02.06.2020 e encontrado em https://brasil.elpais.com/ideas/2020-03-22/o-coronavirus-de-hoje-e-o-mundo-de-amanha-segundo-o-filosofo-byung-chul-han.html

HOBBES, T. (1651) Leviatã. São Paulo, Nova Cultural (col. Os pensadores), 1997.

LA BOÉTIE, E. (1563) A servidão voluntária. São Paulo, Edipro, 2017.

LOCKE, J. (2007) Ensaios Políticos. São Paulo, Martins Fontes.

MERCHIOR, J. G. (2014) 0 liberalismo antigo e moderno. São Paulo, É Realizações.

MÜLLER-LAUTER, W. (1997) A doutrina da vontade de poder em Nietzsche. São Paulo, AnnaBlume. 
NIETZSCHE, F. (2011) “Schopenhauer educador”, in Escritos sobre Educação. tradução, apresentação e notas de Noeli Sobrinho. Rio de Janeiro, PUC-Rio; São Paulo, Loyola.

PETERSON. J. (2018) 12 Regras para a vida. Rio de Janeiro, Alta books, 2018.

REDYSON, D. (2009) Dossiê Schopenhauer. São Paulo, Universo dos Livros.

SCHOPENHAUER, A. (1819) 0 mundo como Vontade e Representação. Tradução de Sá Correia. Rio de Janeiro, Contraponto, 2001.

Artigo recebido em: 06 de junho de 2020

Artigo aceito em: 10 de julho de 2020 